\title{
Emotional mediators of psychological capital on well-being: The role of stress, anxiety, and depression
}

\author{
Fariborz Rahimnia $^{\mathrm{a}}$, Ahmadreza Karimi Mazidi ${ }^{\mathrm{b}^{*}}$, and Zahra Mohammadzadeh ${ }^{\mathrm{c}}$
}

\begin{abstract}
${ }^{a}$ Associate Professor of Management, Faculty of Economic and Administrative Sciences, Ferdowsi University of Mashhad (FUM)
${ }^{b}$ MA in Business Administration, Ferdowsi University of Mashhad (FUM); Researcher of Strategic Studies Institute of Boshra Pajooh ${ }^{c}$ PhD candidate of Organizational Behavior Management, Ferdowsi University of Mashhad (FUM)
\end{abstract}

\section{H R O N I C L E}

\section{Article history:}

Received October 1, 2012

Received in revised format

22 January 2013

Accepted 23 January 2013

Available online

January 252013

Keywords:

Nurses

Psychological Capital

Emotional Well-being

Psychological Well-being

Health care centers

\section{A B S T R A C T}

Researchers have tried to investigate multiple factors affecting employees' social, emotional, and psychological well-being. In this study particularly, nurses' emotional and psychological well-being is considered. Of most important factors affecting well-being in place of work has known to be busy work and stress, constructive and destructive emotions, and psychological capital. Present study considered to test a developed model of psychological capital, constructive and destructive emotions, stress, anxiety, and depression as antecedents of wellbeing. 296 nurses took part in the survey, using path analysis method hypotheses were tested, and the proposed model was evaluated. Results indicated that nurses' high psychological capital increases their constructive emotions, reduces destructive emotions and eventually increase their well-being. The role of destructive emotions was more prominent in increasing wellbeing as well. Furthermore, stress had an incremental influence on well-being. In general, research results emphasize the need for more attention to the components of psychological capital, and intervention and coping strategies. The conclusions of a more detailed is that to improve nurses' well-being the more emphasize should be on decreasing destructive emotions than increasing constructive ones. In addition, keeping an optimal level of stress is necessary for good functioning and improvement of overall well-being.

\section{Introduction}

Today, the fact that organizations are emotional phenomena has been widely accepted. Some organizations, through managing emotions in work settings make significant differences in personal, group and organizational outcomes (Fineman, 1997). Studies have shown that emotions in work have significant effects on employee's job satisfaction (Watson \& Slack, 1993), motivation (Lang, 1995) and information processing (George \& Jones, 2001). Emotional events in the work bring about different emotional reactions (Basch \& Fisher, 1998) which have direct and indirect effects on

*Corresponding author. Tel: +989173160900

E-mail addresses: alef.karimi@gmail.com (A. Karimi Mazidi) 
employee's attitudes and behaviors (Weiss \& Cropanzano, 1996). Behaviors coming from these emotions, depending on direction and severity, affect employee's performance (Kiefer, 2005).

Emotion Management is a fairly new concept in management studies which does not just relate to managers, but every person who wishes a coexistence with his/her emotions should learn how to come up with his/her emotions. Organizations are social entities and health care centers are, we can say, emotional organizations since their emotional aspect is highlighted. So, their managers must be proactive in considering their employee's emotions and not only concentrate on reaching organizational goals but also look for their employee's well-being. To do this, they should continuously monitor their management style and care for their employee's well-being. New contingencies has imposed adding new factors to management model such as PsyCap and these new models should consider in mind the suggestions of emotion management. Employees should have a positive psychological experience from management activates and this positive experience is "wellbeing", which guarantees sustainable organizational performance.

Previous studies have reported four components for PsyCap which include hope, optimism, selfefficacy, and resilience (Luthans et al., 2007) and some potential PsyCaps such as subjective Wellbeing, emotional intelligence, innovation etc. (e.g., Diener et al., 1999; Folkman, 1997; Salovey et al., 2002). Promotion of employee's potential PsyCap is the essence of emotion management (Guojuan et al., 2010). Subjective Well-being and emotional intelligence are more based on emotions and affections and are labeled as "emotion-oriented potential psychological capital". Subjective Wellbeing involves emotional well- being and psychological well-being. In this research, both of them are considered that are named nurse's well-being. Emotional well-being involves elements such as constructive and destructive emotions, life satisfaction and happiness, and psychological well-being involves factors such as self-acceptance, positive relations with others, environmental mastery, purpose in life, and personal growth (Wall, 2011).

Nurse's working conditions have revealed growing need to pay attention to their emotional and psychological capabilities. Nurses should emotionally engage with their work and fairly stable personal characteristics such as self-efficacy and optimism are linked to work engagement (Ouweneel, 2012). However, every nurse experiences both good and bad working days. Nurses are in the front line of servicing and have very close relationship with patients. Their job is often an example of an emotional labor and is known as a hard job that demands stable and controlled reactions and emotions. Especially, working conditions for nurses in Iran is more difficult that makes this study more crucial. Reported by the Nursing Council of Iran in 2012 about the standards difference of the world and Iran medical care, under international standards in medical and surgical wards, every 4 to 6 patient must have a nurse while in Iran there is one nurse per 12 patients and the number of nurses is one third of world standards. The average hours of a nurse at work are somewhat more than its international average, but there is no difference between nurse's holiday and nonholiday working hours to calculate the maximum working hours per week, and nurses' salaries are far below international standards. The maximum difference between nurse and physician salaries in different countries, according to international standards, is four times meanwhile, in some cases this ratio may exceed up to 300 to 500 times in Iran. So, the country is encountered with infusion of nursing students and migration of experienced nurses.

One of the shortcomings of recent researches in emotion management is that it has more attention to high level of destructive emotions (De Raad \& Kokkonen, 2000). Former studies are mainly about Aversive Feelings (e.g., Saarni, 1997), regulation of destructive emotions (e.g., Catanzaro and Mearns, 1990; Smith and Petty, 1995) and bad moods (e.g., Leith \& Baumeister, 1996; Thayer et al., 1994). Only a few studies are available that investigate managing different destructive emotions such as fear and anger (e.g., Buss \& Goldsmith, 1998). According to De Raad and Kokkonen (2000), research about high levels of constructive emotions is rare and can be an interesting subject for 
research. Based on the above, the goal of this research is studying different constructive and destructive emotions in developed model of PsyCap and well-being: Do PsyCap components and experiencing constructive and destructive emotions, stress, anxiety, and depression can be considered as antecedents of psychological and emotional well-being?

\section{Literature Review}

\subsection{Emotion management}

Managing traits and emotions is generally referred to a 'theatrical' conception of social situations in which the person tries to achieve certain goals by a strategic use of emotional expression or of his/her dispositional resources (De Raad \& Kokkonen, 2000). Emotion management is a skill that is mainly about a person's ability to cope with demands of the situation. According to a simple definition by Gross (1999), emotion management or emotion regulation (as cited in De Raad \& Kokkonen, 2000) include the ways that people through which, influence their emotions, the time of perceiving them and how to experience or express these emotions.

Emotion management embraces concepts such as emotional intelligence, emotion regulation and coping with emotions. Emotion management is probably as new as the concept of "trait management", but because of its responsive, contextual and unstable nature, it sounds appropriate to study its potential regulative ability. Recently, this field has been the subject of discussions and empirical research (Kokkonen \& Pulkkinen, 1999). According to a definition from Eisenberg et al. (2000), emotion regulation is the process of initiating, maintaining, modulating, or changing the occurrence, intensity or duration of internal feeling states and emotion-related physiological processes, often in the service of accomplishing one's goals. It also includes physiological management of emotional arousal (Walden \& Smith, 1997) and behaviors related to emotions (Eisenberg, 1998) that reduce stressful levels of emotions to retain emotional openness and flexibility and prevent maladaptive behavior (Cicchetti, 1995). Emotions regulation is also considered as a level of emotional intelligence (Salovey et al., 2002) that encounters with neuroticism (Luminet, 1999), mood swings (Soldz \& Vaillant, 1999) and ineffective problem solving skills (Elliott et al., 1994).

Emotion management strategies can be categorized to Antecedent- and response-focused strategies (Gross, 1999). It is also important to know that all strategies are not necessarily adaptive and effective (Saarni, 1997). As Thompson and Calkins (1996) state, we cannot talk about "optimal emotion management", because every emotion regulation strategy has both benefits and costs for the psychological well-being. Emotion regulation is about both destructive and constructive emotions (Thompson \& Calkins, 1996) and its consequences can be seen in short term and long term (Catanzaro \& Mearns, 1990). Emotion regulation increases as the age goes up (McConatha et al., 1994) and follows certain developmental trends. For example, it gradually shifts from reliance to external sources like caregivers to internal sources such as mentalistic and cognitive sources (Eisenberg, 1998).

\subsection{Well-being}

There are different definitions and inferences for the concept of well-being in the literature. From a hedonic view, well-being is the process in which people avoid pain and discomfort in terms of pleasure attainment (Kahneman et al., 2003). From eudemonic view, well-being relates to something more than just happiness and focuses on meaningfulness and self-awareness and helps people to know their real nature (Waterman, 1993). In a general sense, Ryan and Deci (2001) defined wellbeing as a state of "optimal psychological functioning" that is experienced by people and usually relates to experiencing positive attitudes, emotions and consequences. Psychological well-being 
means the level of psychological functioning in six domains: self-acceptance, positive relations with others, autonomy, environmental mastery, purpose in life, and personal growth. Psychological wellbeing is something more than just not having psychological illness, but also involves general psychological capability to encounter with challenges and stressors in life (Ryff and Singer, 2006).

\subsection{Hypotheses development}

PsyCap goes beyond human capital ('what you know') and social capital ('who you know'), and is more directly concerned with 'who you are' and more importantly 'who you are becoming' (Luthans et al., 2006). One of the factors that promote positive psychological responses to stressful situations is PsyCap (Luthans et al., 2007). According to Luthans et al. (2007), an operational definition for second-order concept of PsyCap is provided as follow (each of the four first-order constructs of PsyCap is provided in parentheses):

an individual's positive psychological state of development that is characterized by: (1) having confidence (self-efficacy) to take on and put in the necessary effort to succeed at challenging tasks; (2) making a positive expectation (optimism) about succeeding now and in the future; (3) persevering toward goals and, when necessary, redirecting paths to goals (hope) in order to succeed; and (4) when beset by problems and adversity, sustaining and bouncing back and even beyond (resilience) to attain success.

Psychological resources theory of Hobfoll (2002), states that many of the psychological constructs are understood as indicators of a wider core construct or "psychological resources". In this sense, the common resource between any of the four capabilities, is a "positive agent striving" (Avey et al., 2008) which represents people's desire to act in their environment as agent, based on positive personal evaluations from the situation. Employees with higher PsyCap possess psychological resources that increase positive behaviors in the workplace. For example, researches have shown that PsyCap relates with more commitment (Luthans et al., 2008), higher performance and satisfaction (Luthans et al., 2007) and more well-being (Avey et al., 2010). Based on the results of previous studies, PsyCap relates positively to employee's positive attitudes such as satisfaction, commitment and well-being and negatively to their negative attitudes such as cynicism and turnover intention (Avey et al., 2011a). Also, Bakker and Demerouti (2008) found that stabilizing of personal- and jobrelated resources in employees, causes distress and leads in Psychological Exhaustion, stress and well-being disorders. PsyCap components including self-efficacy, hope, optimism, and resilience seem to be a barrier against stress and anxiety. Pervious researches confirm a negative relationship between PsyCap and stress and anxiety (Avey et al., 2009) and positive relationship between PsyCap and psychological well-being (Avey et al., 2010). Totally, high levels of PsyCap leads in positive consequences and this mediating role, sustains the process of optimal psychological functioning i.e. well-being (Avey et al., 2011b).

Although it seems to be some overlaps between PsyCap and constructive emotions, there are two main differences between them. First, positive emotions have shorter time frame than PsyCap and change more frequently in a period of the time. Second, positive emotions are typically related to some "personal meaningful situations" (Fredrickson, 2001) while PsyCap can be conceptualized in relationship with both general and specific conditions (Luthans \& Youssef, 2007). Based on Cognitive Meditational Theory of Emotions (Lazarus, 1991; 1993), a person's thinking habits, hope, self- efficacy, optimism and resilience are potential sources for constructive emotions, and these emotions play an important role in attaining to psychological growth and promotion in well-being during the time. Broaden and build (BandB) theory (Fredrickson, 2001), states that emotions such as joy, contentment, and happiness broaden person's mindset and encounter with negative emotions such as depression, stress and anxiety that even trigger of some events such as suicide. Also, constructive emotions shape personal resources such as physical, mental, psychological and social resources that lead in a state of personal well-being at workplace like work engagement (Fredrickson, 1998). This 
theory consists of two main hypotheses: broaden hypothesis and build hypothesis. It means that constructive emotions increase employee's attention and thinking immediately and enables him/her to generate a wider range of ideas. These broadened visions help the person to discover and build important personal resources (Fredrickson, 1998). So, they can make use more effectively of opportunities at work, and be more successful and happy.

Stress appears when a person thinks the demands of the situation are far from his or her ability to respond (Avey et al., 2009). Stress does not necessarily lead in negative consequences, but it can bring about positive ones such as increasing creativity (Le Fevre et al., 2003) or performance (Avey et al., 2009). So, destructive stress is just negative stress and it is those levels of stress that can lead in anxiety. We must distinguish between these two concepts. Stress is the factor that causes feeling of Frustration but anxiety cause the person to feel unrest and fear that is usually the result of long-term stress or existence of several stressful factors simultaneously. So, there is no doubt that high level of stress and anxiety makes destructive consequences such as health problems, increasing bad incidents and exhaustion at work (Bernard \& Krupat, 1994). It has been recognized that when people have more constructive and less destructive emotions, they are healthier, show less destructive work behaviors and experience job burnout less (Diener, 2000; Diener \& Oishi, 2003; Diener et al., 1999). Those who have high levels of constructive emotions are less probable to experience lack of control and unpredictability in their emotional responses to the environment (Avey et al., 2011b). BandB theory states that positive and constructive emotions increase the domain of attention and cognition and thereby shape an upward spiral movement to emotional well-being (Fredrickson and Joiner, 2002).In order to develop and test a PsyCap model (Fig. 1) that presents a mediating role for elaborating how PsyCap influences on well-being, we infer to Avey et al. (2011b). According to literature discussed above, two variables i.e. destructive emotions and depression were added to the model. Current study involves 16 hypotheses as follows:

$\mathbf{H}_{\mathbf{1}}$ : PsyCap is positively associated with constructive emotions.

$\mathbf{H}_{2}$ : PsyCap is negatively associated with destructive emotions.

$\mathbf{H}_{3}, \mathbf{H}_{4}$, and $\mathbf{H}_{5}$ : PsyCap is negatively associated with stress, anxiety and depression.

$\mathbf{H}_{6}$ : Constructive emotions are positively associated with well-being.

$\mathbf{H}_{7}, \mathbf{H}_{8}$, and $\mathbf{H}_{9}$ : Constructive emotions are negatively associated with stress, anxiety and depression.

$\mathbf{H}_{10}$ : Destructive emotions are negatively associated with well-being.

$\mathbf{H}_{11}, \mathbf{H}_{12}$, and $\mathbf{H}_{13}$ : Destructive emotions are positively associated with stress, anxiety and depression.

$\mathbf{H}_{14}, \mathbf{H}_{15}$ and $\mathbf{H}_{16}$ : stress, anxiety and depression are negatively associated with well-being.

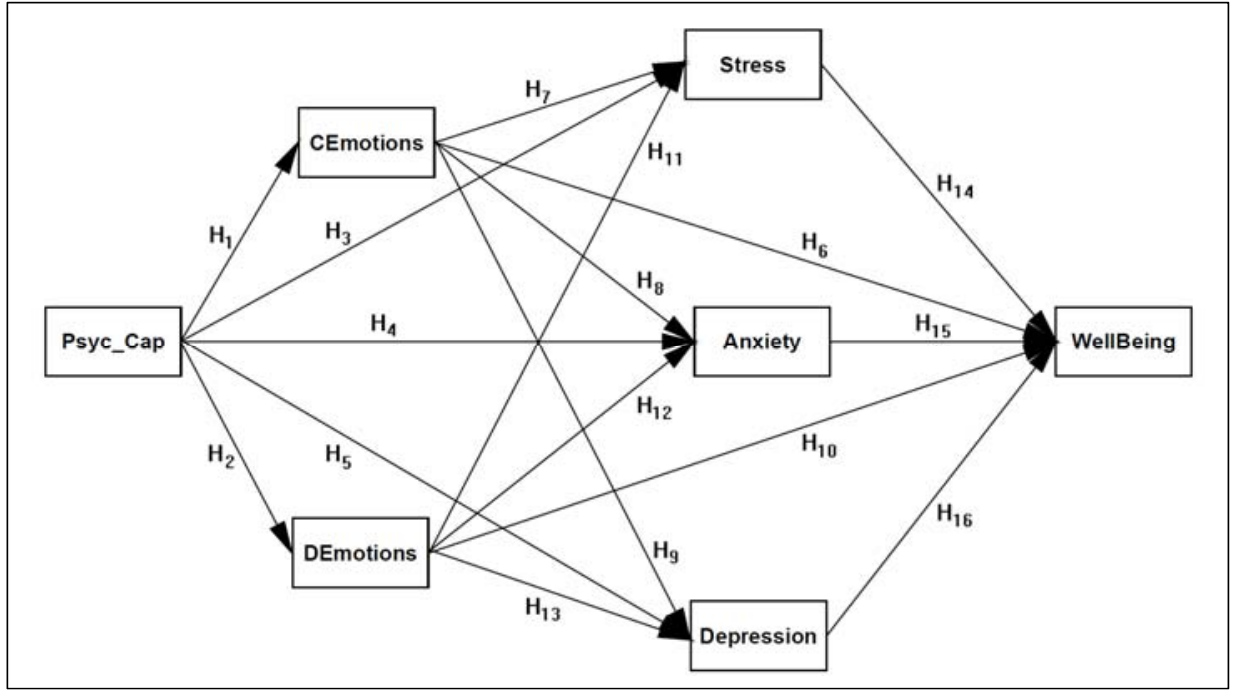

Fig. 1. Research conceptual model 


\section{Methods}

Present study examines above hypotheses using a survey of 296 nurses who work in a large hospital in Iran's northeastern city of Mashhad, in 2012. Total nurses were 750 people. Using Krejcie and Morgan sampling table, a 256 sample was suggested. 360 surveys were distributed and 311 of them returned back. 15 surveys were excluded due to missing information, so, finally 296 eligible questionnaires were available that means a response rate equal to $82.22 \%$. The average age of respondents was 32 years old which ranged from 22 to 59, and 93 of them $(32.3 \%)$ were male. The average tenure was 8 years including the least few months to the most 30 years.

\subsection{Measures}

For gathering data, questionnaires from previous studies in English were used. All measures were translated into Persian and back-translated into English following the method recommended by Brislin (1970) to see if they were translated into Persian accurately and carefully. Construct validity of measures was tested using confirmatory factor analysis (CFA) method to see if the measurement models used are appropriate in testing the hypotheses. Based on the results of the CFA, 3 items of the total 10 in positive affect measure were omitted. Detailed results of this analysis can be seen in findings section (table 2). Reliability was assessed by Cronbach's Alpha coefficients which ranged from 0.77 to 0.92 (see Table 1).

PsyCap was measured using 24-item PsyCap Questionnaire developed by Luthans and colleagues (PCQ-24; Luthans et al., 2006). This questionnaire consists of 6 items for each of PsyCap components that were measured in a 6-point scale (ranging from $1=$ completely disagree, to $6=$ completely agree). Constructive and destructive emotions were assessed using positive and negative worded items in Positive and Negative Affect Schedule Scale (PANAS; Watson et al., 1988). Some examples of positive emotions were interested, excited, strong, and enthusiastic. Alpha coefficient after omitting 3 non-significant items became 0.76 . Some examples of negative emotions included distressed, upset, guilty, and scared. These variables were measured in a 5-point scale (ranging from $1=$ very slightly, to $5=$ extremely). Stress, anxiety and depression were measured using 21-item Depression, Anxiety and Stress Scale which is a 4-point scale (ranging from 0=did not apply to me at all, to 3=applied to me very much) (DASS-21; Lovibond and Lovibond, 1995). Finally, wellbeing was assessed using General Health Questionnaire (GHQ-12; Goldberg and Williams, 1988) that is a commonly accepted instrument to measure well-being (Avey et al., 2011b). Each item is rated on a 4-point scale (ranging from $1=$ seldom, to $4=$ often).

\subsection{Data Analysis}

Path analysis method was used to analyze the data and evaluate non-experimental causal relationships between variables. So, all variables were entered the model at once and their reciprocal effects were considered too. To conduct Pearson correlation analysis and calculate descriptive statistics, SPSS was used. Confirmatory factor analysis for testing validity of measures, casual relationships between variables in the suggested model, and subsequent analyses were conducted using AMOS.

\section{Results}

Since one of the requirements of conducting multivariable analysis is the relationship between variables, Pearson correlation analysis was performed. Results revealed that all correlations are significant. The highest correlation was between anxiety and depression $(r=0.77)$ and the least correlation was between destructive emotions and constructive emotions $(\mathrm{r}=-0.26)$. Table 1 shows the means, standard deviations and correlations between variables. The amount of Cronbach's alpha coefficients is also seen in the table that confirms the reliability of the measures for each variable. 
Table 1

Means, Standard Deviations, Internal Reliabilities, and Inter-correlations

\begin{tabular}{|c|c|c|c|c|c|c|c|c|c|}
\hline Variables & Mean & SD & 1 & 2 & 3 & 4 & 5 & 6 & 7 \\
\hline 1. PsyCap & 4.32 & 0.699 & $(0.92)$ & & & & & & \\
\hline 2. Constructive Emotions & 3.51 & 0.686 & 0.45 & $(0.76)$ & & & & & \\
\hline 3. Destructive Emotions & 2.36 & 0.776 & -0.38 & -0.26 & $(0.83)$ & & & & \\
\hline 4. Stress & 1.19 & 0.648 & -0.43 & -0.32 & 0.53 & $(0.84)$ & & & \\
\hline 5. Anxiety & 0.88 & 0.644 & -0.38 & -0.44 & 0.54 & 0.68 & $(0.77)$ & & \\
\hline 6. Depression & 1.06 & 0.696 & -0.40 & -0.41 & 0.53 & 0.75 & 0.77 & $(0.85)$ & \\
\hline 7. well being & 2.96 & 0.499 & 0.51 & 0.57 & -0.63 & -0.49 & -0.61 & -0.63 & $(0.79)$ \\
\hline
\end{tabular}

Note. $\mathrm{N}=296 ; \mathrm{p}<0.01$; Average coefficient alpha internal reliabilities appear in parentheses.

\subsection{Assessing the Measures and Common Method Bias}

As a precursor to path analysis, the measures were assessed to see if each item is statistically significant loaded to its relevant construct. To do this, we conducted confirmatory factor analysis (CFA) for both distinct measures and the overall measurement tool but for brevity, results of all CFA models are presented in a single table (see table 2). The number of measures, there will be measurement models in this study which cover all 7 variables. All of four measurement models as well as overall measurement model were evaluated through regression weights significance, overall model fit indices, and Cronbach's alpha coefficients. As previously mentioned, except 3 of 10 items in constructive emotions of PANAS measurement model which were non-significant, the rest were significantly loaded to their constructs. Cronbach's alpha for all measurement models exceed 0.70 and fit indices of all CFA models were acceptable. These indices only for overall measurement model can be seen in Table 2.

Table 2

Results of confirmatory factor analysis (CFA) for distinct and overall measurement models

\begin{tabular}{|c|c|c|c|c|c|c|c|}
\hline \multicolumn{2}{|c|}{ Measure: DASS-21 } & \multicolumn{2}{|c|}{ Measure: PCQ-24 } & \multicolumn{2}{|c|}{ Measure: GHQ-12 } & \multicolumn{2}{|c|}{ Measure: PANAS } \\
\hline Items & FLs & Items & FLs & Items & FLs & Items & FLs \\
\hline \multicolumn{2}{|c|}{ Stress $(0.80)$} & \multicolumn{2}{|c|}{ Self-efficacy $(0.76)$} & Q46 & 0.47 & \multicolumn{2}{|c|}{ Positive Affects (0.48) } \\
\hline Q1 & 0.49 & Q22 & 0.82 & Q47 & 0.30 & Q58 & $0.03 *$ \\
\hline Q6 & 0.46 & Q23 & 0.80 & Q48 & 0.48 & Q60 & $0.08^{*}$ \\
\hline Q8 & 0.66 & Q24 & 0.72 & Q49 & 0.45 & Q62 & 0.45 \\
\hline Q11 & 0.82 & Q25 & 0.80 & Q50 & 0.44 & Q66 & 0.57 \\
\hline Q12 & 0.79 & Q26 & 0.63 & Q51 & 0.58 & Q67 & 0.67 \\
\hline Q14 & 0.68 & Q27 & 0.58 & Q52 & 0.54 & Q69 & $0.02 *$ \\
\hline Q18 & 0.58 & \multicolumn{2}{|c|}{ Hope (0.91) } & Q53 & 0.48 & Q71 & 0.62 \\
\hline \multicolumn{2}{|c|}{ Anxiety (0.84) } & Q28 & 0.69 & Q54 & 0.50 & Q73 & 0.53 \\
\hline Q2 & 0.57 & Q29 & 0.78 & Q55 & 0.37 & Q74 & 0.46 \\
\hline Q4 & 0.65 & Q30 & 0.72 & Q56 & 0.44 & Q76 & 0.44 \\
\hline Q7 & 0.61 & Q31 & 0.70 & Q57 & 0.40 & \multicolumn{2}{|c|}{ Negative Affects (-0.57) } \\
\hline Q9 & 0.53 & Q32 & 0.69 & & & Q59 & 0.60 \\
\hline Q15 & 0.80 & Q33 & 0.70 & & & Q61 & 0.59 \\
\hline Q19 & 0.59 & \multicolumn{2}{|c|}{ Resiliency (0.77) } & & & Q63 & 0.41 \\
\hline Q20 & 0.69 & Q34 & 0.21 & & & Q64 & 0.60 \\
\hline \multicolumn{2}{|c|}{ Depression (0.90) } & Q35 & 0.74 & & & Q65 & 0.46 \\
\hline Q3 & 0.56 & Q36 & 0.66 & & & Q68 & 0.37 \\
\hline Q5 & 0.59 & Q37 & 0.61 & & & Q70 & 0.48 \\
\hline Q10 & 0.76 & Q38 & 0.73 & & & Q72 & 0.73 \\
\hline Q13 & 0.69 & Q39 & 0.74 & & & Q75 & 0.66 \\
\hline Q16 & 0.80 & \multicolumn{2}{|c|}{ Optimism (0.77) } & & & Q77 & 0.67 \\
\hline Q17 & 0.56 & Q40 & 0.48 & & & & \\
\hline \multirow[t]{5}{*}{ Q21 } & 0.67 & Q41 & 0.75 & & & & \\
\hline & & Q42 & 0.58 & & & & \\
\hline & & Q43 & 0.66 & & & & \\
\hline & & Q44 & 0.33 & & & & \\
\hline & & Q45 & 0.59 & & & & \\
\hline
\end{tabular}

$\chi_{128}^{2}=230.59\left(\chi^{2} / \mathrm{df}=1.80\right) ; \mathrm{P}=0.000 ;$ Normed Fit Index $(\mathrm{NFI})=0.92 ;$ Comparative Fit Index $(\mathrm{CFI})=0.96$; Goodness-of-Fit Index $(\mathrm{GFI})=0.93$; Root Mean Squared Residual (RMR) $=0.045$; Root Mean Squared Error of Approximation (RMSEA) $=0.052$

Note. $\mathrm{N}=296$; The values in the table are standardized regression weights; Factor loadings (FLs) of constructs are in parentheses; *:Non-

significant items at confidence level of 0.95 . 
Common method bias refers to the variance that is attributed to the measurement method rather than the constructs, because of the common method used in data collection (Buckley et al., 1990). Since, this study is single-method with cross-sectional research design and all data are self-reported, data are likely to be susceptible to common method variance (CMV) that is one of the most important concerns in social researches. So, to decrease the possibility of CMV (Podsakoff et al., 2003) we used various response formats (4, 5, and 6 point scales) and conducted a Harman's single-factor test by performing an exploratory factor analysis (EFA) using SPSS v.19. To do this test, all the items of the principal constructs in the study are subject to EFA, and there will be a substantial common method bias when a single factor emerges or one general factor accounts for the majority (over 50\%) of the variance. The results of the un-rotated principal components factor analysis revealed that there existed 5 distinct factors with eigenvalues greater than 1.0. The first factor with the greatest eigenvalue did not account for the majority of the variance (about $35 \%$ which is significantly less than half) and the five factors together accounted for $65 \%$ of the total variance (Podsakoff et al., 2003); therefore, CMV is not of great concern and the results of this study could not be attributed to common method bias.

\subsection{Fit indices for confirmation of the model}

To assess the validity of the relationships between variables and total fitness of the model, multivariable analysis and specifically path analysis was used. For a satisfactory fit to data, normed Chi-square $\left(\chi^{2 / \mathrm{df}}\right)$ of the model should be less than 3, Normed Fit Index (NFI), Comparative Fit Index (CFI), and Goodness-of-Fit Index (GFI) more than 0.90, Root Mean Squared Residual (RMR) less than 0.09 and Root Mean Squared Error of Approximation (RMSEA) less than 0.05. Figure 2 shows the graphical output of AMOS for fitted model and the amount and direction of the relationships between variables can be seen in it. It is noteworthy that the model was modified by indices (MI) in AMOS to provide more realistic results. So, Covariance relationships were reasonably established among error variables of each measure constructs. These Covariance relationships were significantly different from zero at the 0.05 level, whilst the possibility of multicollinearity is also reduced to a considerable extent.

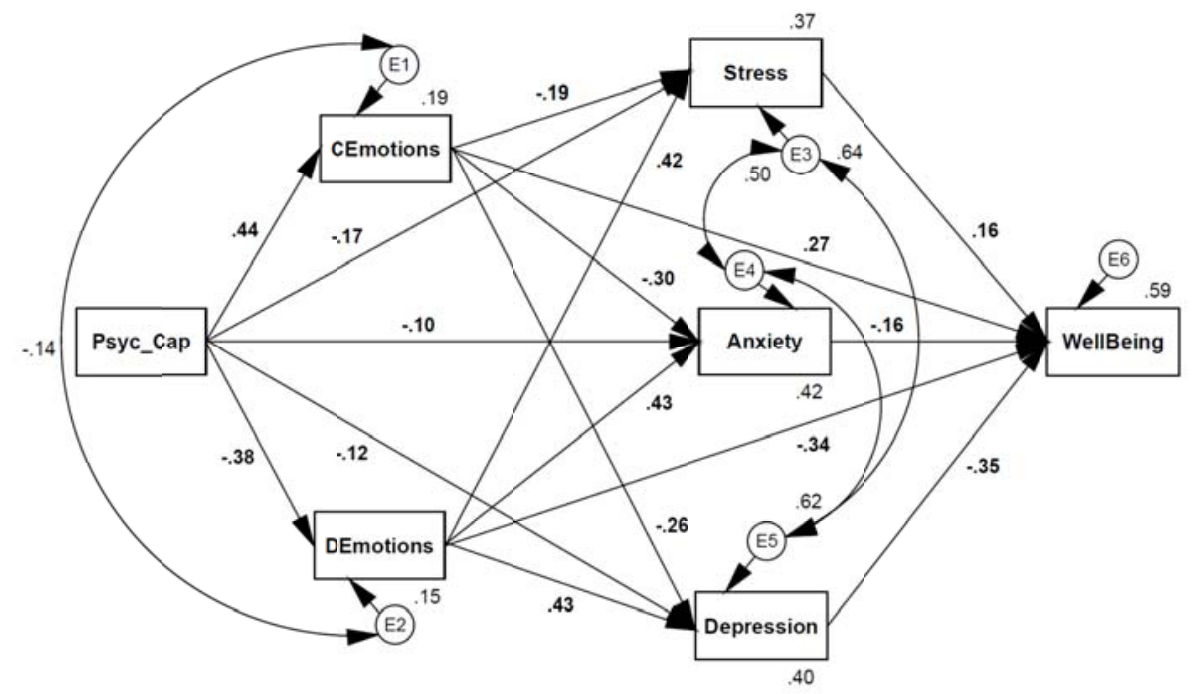

Fig. 2. Path model along with standardized coefficients

In the fitted model, $\chi^{2}$ equals to 2.062 and since $p=0.151$ (more than 0.05 ), it is non-significant. $\chi^{2} / \mathrm{df}$ equals to 2.062 ( $\mathrm{df}=1$ ), NFI, CFI and GFI are orderly 0.998, 0.999 and 0.998, RMR equals to 0.008, and RMSEA equals to 0.06. Except for RMSEA, all indices are more desirable than cut-off points and confirm the model's high validity. Hoelter's index $(=231)$, which shows the adequacy of sampling, also indicates that the sample size is greater than the critical value $(n=296>231)$. 


\subsection{Hypotheses testing}

Standardized path coefficient and significance level was used to test the hypotheses. In all paths, significance level was 0.95 and accepted error level was 0.05 . As it can be seen, 16 hypotheses were developed. To test them, path analysis was conducted which the results are available in table 3 . A hypotheses is confirmed when its significance level is less than 0.05 or its significance index is more than 1.96 or less than -1.96 . As the table 3 shows, all the relationships are significant. The highest direct predicting amount pertains to prediction of constructive emotions by PsyCap $(\beta=0.44)$ and the least predicting amount i.e. absolute level, is in the relationship between anxiety and PsyCap ( $\beta=$ 0.10). The indirect effect of PsyCap on well-being was confirmed in all paths. The least amount of indirect effect relates to the effect of constructive emotions on well-being $(-0.10)$ which is due to the positive effect of stress on well-being; because the positive effect of this relationship reduces the algebraic sum of the effect coefficient of each of constructive emotions, destructive emotions, and PsyCap on well-being. Between three variables i.e. PsyCap, constructive, and destructive emotions that have the ability to affect well-being indirectly, the least amount of total effect relates to constructive emotions (equal to 0.37). There is not any direct path between main independent variable i.e. PsyCap and dependent variable i.e. well-being, but PsyCap through indirect path of PsyCap/destructive emotions/depression can best predict the variance in well-being $(\beta=0.057)$. Indirect effect of PsyCap on well-being, which in this model equals to total effect, is 0.384 . In terms of the squared multiple correlations (SMC), 59\% of the variance in well-being is explained by the PsyCap model.

Table 3

Path coefficients, Significance level and beta for hypotheses testing

\begin{tabular}{lcccc}
\hline hypothesis & Path coefficient & Sig & $\boldsymbol{\beta}$ & Result \\
\hline PsyCap/Constructive Emotions & 0.44 & 0.000 & 8.414 & supported \\
PsyCap /Destructive Emotions & -0.38 & 0.000 & -7.108 & supported \\
PsyCap/Stress & -0.17 & 0.002 & -3.088 & supported \\
PsyCap /Anxiety & -0.10 & 0.047 & -1.983 & supported \\
PsyCap /Depression & -0.12 & 0.018 & -2.360 & supported \\
Constructive Emotions/Well-being & 0.27 & 0.000 & 6.317 & supported \\
Constructive Emotions/Stress & -0.19 & 0.000 & -3.642 & supported \\
Constructive Emotions/Anxiety & -0.30 & 0.000 & -6.109 & supported \\
Constructive Emotions/Depression & -0.26 & 0.000 & -5.099 & supported \\
Destructive Emotions/Well-being & -0.34 & 0.000 & -7.330 & supported \\
Destructive Emotions/Stress & 0.42 & 0.000 & 8.294 & supported \\
Destructive Emotions/Anxiety & 0.43 & 0.000 & 8.792 & supported \\
Destructive Emotions/Depression & 0.43 & 0.000 & 8.762 & supported \\
Stress/Well-being & 0.16 & 0.008 & 2.662 & Not supported \\
Anxiety/Well-being & -0.16 & 0.013 & -2.473 & supported \\
Depression/Well-being & -0.35 & 0.000 & -4.923 & supported \\
\hline
\end{tabular}

\section{Discussion}

The goal of this research is to assess a model of PsyCap and well-being and to investigate predictability of psychological and emotional well-being of nurses through PsyCap, constructive, and destructive emotions and feelings. In order to make valid results, data were analyzed using different statistical techniques. Pearson correlation analysis showed significant relationships between all variables, path analysis strongly confirmed validity of the research model, and finally, relationships significance were all confirmed. These findings are consistent with the results of previous studies (Avey et al., 2009; Bernard \& Krupat, 1994; Diener, 2000; Diener et al., 2003; Diener et al., 1999; Luthans et al., 2008) except for the relationship between stress and well-being, which is seemingly inconsistent with studies stated in theoretical background (Avey et al., 2009; Bernard \& Krupat, 1994). 
A reason for positive effect of stress on well-being may be the simultaneous effects of variables in the model and special context that study has been conducted, since the hospital that the data has been acquired is also an educational center. It's also possible that the positive effect of stress on well-being is due to the low level of employee's stress. Employee's average score of stress is 1.19 (maximum level equal to 3 ) that seems to be a relatively low score although it is not desirable, and shows the low level of stress in nurses. Considering previous studies, alongside negative consequences, stress has also benefits such as increasing in creativity and performance (Avey et al., 2009; Le Fevre et al., 2003). Regarding positive effect of stress on well-being, it could be inferred that this positive consequence stems from the low level of stress.

In spite of specifying a negative relationship between stress and well-being in the literature (e.g., Bernard \& Krupat, 1994), we could not find a positive relationship between stress and well-being in our efforts. In other words, we could not find any research, which shows that the stress could have both positive and negative effects on well-being. Future researchers may study about it. But generally, this study confirmed that stress has an optimum level that below this level, increasing in stress leads in increasing well-being and beyond that point, stress is harmful for well-being. In this research, regarding the score of 1.19 for stress (below the average), standardized beta coefficient for the effect of stress on well-being was found to be 0.16 , and we may predict that as the level of stress goes down, the positive effect of stress on well-being will be more, and as the level of stress goes near to the maximum level (i.e. score 3), the negative effect of stress on well-being will tense more. This can be an interesting finding both as a theoretical and practical finding.

Based on the reported values of modified model in AMOS, the highest direct predicting capability belongs to prediction of constructive emotions through PsyCap $(\beta=0.44)$ and the most indirect predicting capability relates to the prediction of well-being through PsyCap $(\beta=0.38)$. But, the most total predicting power belongs to prediction of well-being through destructive emotions $(\beta=-0.48)$ which means that destructive emotions, with $23.91 \%$, have the most powerful role in predicting wellbeing. The average scores for all variables show that PsyCap, constructive emotions and well-being are above average (with scores $0.72,0.70$ and 0.74 of 1 ) and destructive emotions, stress, anxiety and depression (with scores $0.47,0.39,0.29$ and 0.35 of 1) are below the average. It should be noted that regarding different scales of measures, all scores are calculated from 1 so that their comparison is possible. Hence, it can be said that the status of all variables is relatively good but none of them is satisfactory. Well-being and anxiety have the best situation.

\section{Conclusion}

To increase nurse's well-being, it was found that reduction of destructive emotions has the most powerful effect. So managers of these environments are suggested to pay more attention to nurses' destructive emotions. As we found, with investing more on PsyCap components through the mediating role of constructive and destructive emotions, managers can enhance nurse's well-being.

Personal and social problems that stem from intemperate and chronic destructive emotions cause a continuum from anxiety and depression to aggression and heart diseases. Some of the coping and intervention strategies include Relaxation Therapies, Behavioral Therapies (aim to increase pleasant activities), cognitive therapies (aim to train optimism), and coping strategies marked by finding positive meaning within and despite adversity (Fredrickson, 2000). These strategies lead in optimizing nurse's health and well-being and grow their constructive emotions. Constructive emotions, not only encounter with destructive ones, but also widen the scope of nurse's habitual thinking and create personal sources for beating destructive emotions in them. Empirical findings also indicated that relaxation therapies treat the problems that root in destructive emotions including anxiety (Lee et al., 2007), stress and depression (Shapiro et al., 1998). These treats include traditional forms such as yoga and meditation and modern forms such as progressive muscle relaxation and 
Biofeedback (Fredrickson, 2000). Finally, participating in spiritual and religious activities, or at least believing in meaningfulness of life can increase the probability of employee's optimism and positive psychological states (Folkman, 1997).

This research opened new avenues for future researches. Since it is possible that nurse's emotions would be various in different hours of a day regarding the number of patients, it can be suggested that for a more closed investigation, nurses be studied in different hours a day and their survey findings be compared. Also, the PsyCap and well-being model can be tested in other situations and environments to be verified, so that a more accurate and comprehensive model could be developed. Another variable that can be added in this model is "emotional labor". For example, strategies that nurses use to adapt themselves with unpleasant feelings may lead in their stress and anxiety. Future studies can elaborate the association of emotional labor with the model of PsyCap and well-being.

\section{Conflict of interest}

There is no conflict of interest.

\section{References}

Avey, J.B., Luthans, F., Smith, R.M., \& Palmer, N.F. (2010). Impact of positive psychological capital on employee wellbeing over time. Journal of Occupational Health Psychology, 15(1), 17-28. doi: 10.1037/a0016998

Avey, J.B., Luthans, F., \& Jensen, S.M. (2009). Psychological capital: A positive resource for combating employee stress and turnover. Human Resource Management, 48(5), 677-693.

Avey, J.B., Reichard, R.J., Luthans, F., \& Mhatre, K.H. (2011). Meta-analysis of the impact of positive psychological capital on employee attitudes, behaviors, and performance. Human Resource Development Quarterly, 22(2), 127-152. doi: 10.1002/hrdq.20070

Avey, J.B., Wernsing, T.S., \& Luthans, F. (2008). Can Positive Employees Help Positive Organizational Change? Impact of Psychological Capital and Emotions on Relevant Attitudes and Behaviors. The Journal of Applied Behavioral Science, 44(1), 48-70. doi: 10.1177/0021886307311470

Avey, J.B., Wernsing, T.S., \& Mhatre, K.H. (2011). A Longitudinal Analysis of Positive Psychological Constructs and Emotions on Stress, Anxiety, and Well-Being. Journal of Leadership \& Organizational Studies, 18(2), 216-228. doi: 10.1177/1548051810397368

Bakker, A.B., \& Demerouti, E. (2008). Towards a model of work engagement. Career Development International, 13(3), 209-223.

Basch, J., \& Fisher, C.D. (1998). Affective events-emotions matrix: A classification of work events and associated emotions. School of Business Discussion Papers, Paper 65.

Bernard, L.C., \& Krupat, E. (1994). Health Psychology: Biopsychosocial Factors in Health and Illness: NewYork: Harcourt Brace College Publications.

Brislin, R.W. (1970). Back-Translation for Cross-Cultural Research. Journal of Cross-Cultural Psychology, 1(3), 185-216. doi: 10.1177/135910457000100301

Buckley, M.R., Cote, J.A., \& Comstock, S.M. (1990). Measurement Errors in the Behavioral Sciences: The Case of Personality/Attitude Research. Educational and Psychological Measurement, 50(3), 447-474. doi: $10.1177 / 0013164490503001$

Buss, K.A., \& Goldsmith, H.H. (1998). Fear and Anger Regulation in Infancy: Effects on the Temporal Dynamics of Affective Expression. Child Development, 69(2), 359-374. doi: 10.1111/j.14678624.1998.tb06195.x

Catanzaro, S.J., \& Mearns, J. (1990). Measuring generalized expectancies for negative mood regulation: Initial scale development and implications. Journal of Personality Assessment, 54(3-4), 546-563.

Cicchetti, D., Ackerman, B.P., \& Izard, C.E. (1995). Emotions and emotion regulation in developmental psychopathology. Development and Psychopathology, 7(01), 1-10. doi: doi:10.1017/S0954579400006301

De Raad, B., \& Kokkonen, M. (2000). Traits and emotions: a review of their structure and management. European Journal of Personality, 14(5), 477-496. doi: 10.1002/1099-0984(200009/10)14:5<477::aidper396>3.0.co;2-i 
Diener, E. (2000). Subjective well-being: The science of happiness and a proposal for a national index. American psychologist, 55(1), 34-43.

Diener, E., Oishi, S., \& Lucas, R.E. (2003). Personality, Culture, and Subjective Well-Being: Emotional and Cognitive Evaluations of Life. Annual review of psychology, 54(1), 403-425. doi: doi:10.1146/annurev.psych.54.101601.145056

Diener, E., Suh, E.M., Lucas, R.E., \& Smith, H.L. (1999). Subjective well-being: Three decades of progress. Psychological bulletin, 125(2), 276-302.

Eisenberg, N. (1998). Introduction. In N. Eisenberg (Ed.), Social, Emotional, and Personality Development. New York: John Wiley \& Sons Inc.

Eisenberg, N., Fabes, R.A., Guthrie, I.K., \& Reiser, M. (2000). Dispositional emotionality and regulation: their role in predicting quality of social functioning. Journal of Personality and Social Psychology, 78(1), 136157.

Elliott, T.R., Herrick, S.M., MacNair, R.R., \& Harkins, S.W. (1994). Personality correlates of self-appraised problem solving ability: Problem orientation and trait affectivity. Journal of Personality Assessment, 63(3), 489-505.

Fineman, S. (1997). Emotion and Management Learning. Management Learning, 28(1), 13-25. doi: $10.1177 / 1350507697281002$

Folkman, S. (1997). Positive psychological states and coping with severe stress. Social Science \& amp; Medicine, 45(8), 1207-1221. doi: 10.1016/s0277-9536(97)00040-3

Fredrickson, B.L. (1998). What good are positive emotions? Review of General Psychology, 2(3), 300-319.

Fredrickson, B.L. (2000). Cultivating positive emotions to optimize health and well-being. Prevention \& Treatment, 3(1), No Pagination Specified.

Fredrickson, B.L. (2001). The role of positive emotions in positive psychology: The broaden-and-build theory of positive emotions. American psychologist, 56(3), 218-226.

Fredrickson, B.L., \& Joiner, T. (2002). Positive Emotions Trigger Upward Spirals Toward Emotional WellBeing. Psychological Science, 13(2), 172-175. doi: 10.1111/1467-9280.00431

George, J.M., \& Jones, G.R. (2001). Towards a Process Model of Individual Change in Organizations. Human Relations, 54(4), 419-444. doi: 10.1177/0018726701544002

Goldberg, D., \& Williams, P. (1988). A user's guide to the General Health Questionnaire. Slough: NferNelson.

Gross, J.J. (1999). Emotion regulation: Past, present, future. Cognition \& Emotion, 13(5), 551-573.

Guojuan, Z., Shuling, W., \& Junli, Z. (2010). Research on the Happiness Management Model from the Perspective of Psychological Capital. Paper presented at the Proceedings of the $7^{\text {th }}$ International Conference on Innovation \& Management.

Hobfoll, S.E. (2002). Social and psychological resources and adaptation. Review of General Psychology, 6(4), 307.

Kahneman, D., Diener, E., \& Schwarz, N. (2003). Well-being: The foundations of hedonic psychology: New York, NY: Russell Sage Foundation Publications.

Kiefer, T. (2005). Feeling bad: Antecedents and consequences of negative emotions in ongoing change. Journal of Organizational Behavior, 26(8), 875-897.

Kokkonen, M., \& Pulkkinen, L. (1999). Emotion regulation strategies in relation to personality characteristics indicating low and high self-control of emotions. Personality and Individual Differences, 27(5), 913-932. doi: 10.1016/s0191-8869(99)00040-9

Lang, P.J. (1995). The emotion probe: Studies of motivation and attention. American psychologist, 50(5), $372-$ 385.

Lazarus, R.S. (1991). Emotion and adaptation: New York, NY: Oxford University Press, USA.

Lazarus, R.S. (1993). From psychological stress to the emotions: A history of changing outlooks. Annual Review of Psychology, 44, 1-21.

Le Fevre, M., Matheny, J., \& Kolt, G.S. (2003). Eustress, distress, and interpretation in occupational stress. Journal of Managerial Psychology, 18(7), 726-744.

Lee, S.H., Ahn, S.C., Lee, Y.J., Choi, T.K., Yook, K.H., \& Suh, S.Y. (2007). Effectiveness of a meditationbased stress management program as an adjunct to pharmacotherapy in patients with anxiety disorder. Journal of Psychosomatic Research, 62(2), 189-195. doi: 10.1016/j.jpsychores.2006.09.009

Leith, K.P., \& Baumeister, R.F. (1996). Why do bad moods increase self-defeating behavior? Emotion, risk tasking, and self-regulation. Journal of Personality and Social Psychology, 71(6), 1250-1267. 
Lovibond, P.F., \& Lovibond, S.H. (1995). The structure of negative emotional states: Comparison of the Depression Anxiety Stress Scales (DASS) with the Beck Depression and Anxiety Inventories. Behaviour Research and Therapy, 33(3), 335-343. doi: 10.1016/0005-7967(94)00075-u

Luminet, O., Bagby, R.M., Wagner, H., Taylor, G.J., \& Parker, J.D.A. (1999). Relation between alexithymia and the five-factor model of personality: a facet-level analysis. Journal of Personality Assessment, 73(3), 345-358.

Luthans, F., Avey, J.B., Avolio, B.J., Norman, S.M., \& Combs, G.M. (2006). Psychological capital development: toward a micro-intervention. Journal of Organizational Behavior, 27(3), 387-393. doi: 10.1002/job.373

Luthans, F., Avolio, B.J., Avey, J.B., \& Norman, S.M. (2007). Positive Psychological Capital: Measurement and Relationship with Performance and Satisfaction. Personnel Psychology, 60(3), 541-572. doi: 10.1111/j.1744-6570.2007.00083.x

Luthans, F., Norman, S.M., Avolio, B.J., \& Avey, J.B. (2008). The mediating role of psychological capital in the supportive organizational climate-employee performance relationship. Journal of Organizational Behavior, 29(2), 219-238. doi: 10.1002/job.507

Luthans, F., \& Youssef, C.M. (2007). Emerging Positive Organizational Behavior. Journal of Management, 33(3), 321-349. doi: 10.1177/0149206307300814

McConatha, J.T., Lightner, E., \& Deaner, S.L. (1994). Culture, age, and gender as variables in the expression of emotions. Journal of Social Behavior \& Personality, 9(3), 481-488.

Ouweneel, E., Le Blanc, P.M., Schaufeli, W.B., \& Van Wijhe, C.I. (2012). Good morning, good day: A diary study on positive emotions, hope, and work engagement. Human Relations, 65(9), 1129-1154. doi: $10.1177 / 0018726711429382$

Podsakoff, P.M., MacKenzie, S.B., Lee, J.Y., \& Podsakoff, N.P. (2003). Common method biases in behavioral research: a critical review of the literature and recommended remedies. Journal of applied psychology, 88(5), 879-903.

Ryan, R.M., \& Deci, E.L. (2001). On happiness and human potentials: A review of research on hedonic and eudaimonic well-being. Annual review of psychology, 52(1), 141-166.

Ryff, C.D., \& Singer, B.H. (2006). Best news yet on the six-factor model of well-being. Social Science Research, 35(4), 1103-1119.

Saarni, C. (1997). Coping with Aversive Feelings. Motivation and Emotion, 21(1), 45-63. doi: 10.1023/a:1024474314409

Salovey, P., Mayer, J.D., \& Caruso, D. (2002). The positive psychology of emotional intelligence. In C. Snyder \& S. Lopez (Eds.), The Handbook of Positive Psychology (Vol. 159, pp. 171). New York: Oxford University Press.

Shapiro, S.L., Schwartz, G.E., \& Bonner, G. (1998). Effects of Mindfulness-Based Stress Reduction on Medical and Premedical Students. Journal of Behavioral Medicine, 21(6), 581-599. doi: 10.1023/a:1018700829825

Smith, S.M., \& Petty, R.E. (1995). Personality moderators of mood congruency effects on cognition: The role of self-esteem and negative mood regulation. Journal of Personality and Social Psychology, 68(6), 10921107.

Soldz, S., \& Vaillant, G.E. (1999). The Big Five Personality Traits and the Life Course: A 45-Year Longitudinal Study. Journal of Research in Personality, 33(2), 208-232. doi: 10.1006/jrpe.1999.2243

Thayer, R.E., Newman, J.R., \& McClain, T.M. (1994). Self-regulation of mood: Strategies for changing a bad mood, raising energy, and reducing tension. Journal of Personality and Social Psychology, 67(5), 910-925.

Thompson, R., \& Calkins, S. (1996). The double-edged sword: Emotional regulation for children at risk. Development and Psychopathology, 8(01), 163-182. doi: doi:10.1017/S0954579400007021

Walden, T.A., \& Smith, M.C. (1997). Emotion regulation. Motivation and Emotion, 21(1), 7-25.

Wall, D. (2011). The Impact of Family Dynamics on Psychological Well-Being in Adult Adoptees. (Doctoral dissertation), Walden University.

Waterman, A.S. (1993). Two conceptions of happiness: Contrasts of personal expressiveness (eudaimonia) and hedonic enjoyment. Journal of Personality and Social Psychology, 64(4), 678-691.

Watson, D., Clark, L.A., \& Tellegen, A. (1988). Development and validation of brief measures of positive and negative affect: the PANAS scales. Journal of Personality and Social Psychology, 54(6), 1063-1070.

Watson, D., \& Slack, A.K. (1993). General Factors of Affective Temperament and Their Relation to Job Satisfaction over Time. Organizational Behavior and Human Decision Processes, 54(2), 181-202. doi: 10.1006/obhd.1993.1009 
Weiss, H.M., \& Cropanzano, R. (1996). Affective events theory: A theoretical discussion of the structure, causes and consequences of affective experiences at work. Research in Organizational Behavior, 18, 1-74. 